\title{
SUBCONJUNCTIVAL BETAMETHASONE IS OF BENEFIT AFTER CATARACT SURGERY
}

\author{
MELANIE C. CORBETT, MELANIE HINGORANI, JONATHAN E. BOULTON and \\ JOHN S. SHILLING \\ London
}

\begin{abstract}
SUMMARY
Following cataract extraction, the intraocular inflammatory response is particularly marked in some patients, who then require more intensive post-operative care. This prospective randomised double-masked controlled trial of 246 patients undergoing cataract extraction assessed the efficacy and safety of a prophylactic subconjunctival injection of betamethasone (Betnesol, Glaxo) in improving the post-operative course. Betamethasone injected subconjunctivally at the end of cataract extraction significantly reduces anterior segment inflammation $(p<0.05)$ on the first post-operative day. It also reduces the need for additional steroid treatment and in-patient stay $(p<0.05)$. The benefits are most marked in those patients prone to a greater inflammatory response: especially those with previous intraocular inflammation $(p<0.01)$, but also those with racial pigmentation or difficult surgery. There was no evidence of adverse effects following betamethasone; in particular there was no endophthalmitis or steroidinduced elevation of intraocular pressure. We therefore conclude that subconjunctival injection of betamethasone is a practical, safe and effective means of improving the quality and efficiency of patient care.
\end{abstract}

Over the last 20 years, cataract extraction has become an increasingly successful and safe procedure. ${ }^{1-3}$ In-patient stay and post-operative rehabilitation time have been dramatically reduced ${ }^{4}$ with many patients now having their operations performed as day cases. ${ }^{5-7}$ It is therefore becoming increasingly important to prevent complications which require more intensive post-operative care.

Following cataract extraction, the intraocular inflammatory response is particularly marked in some patients, who then require additional post-operative examinations and treatment, or prolonged in-patient stay ${ }^{8-10}$ Therefore to maintain clinical standards and reduce pressure on the in-patient and out-patient services, it is necessary to provide optimal anti-inflammatory prophylaxis. Current

From: Department of Ophthalmology, Greenwich District Hospital, Vanbrugh Hill, Greenwich, London SE10 9HE, UK.

Correspondence to: Miss Melanie C. Corbett, FRCS, Department of Ophthalmology, St Thomas'Hospital (Block 8), Lambeth Palace Road, London SE1 7EH, UK. opinion is divided as to the best route of administration, and whether these measures should be instituted immediately after surgery or on the first post-operative day.

The aim of this prospective randomised double-masked controlled trial was to determine the role of prophylactic subconjunctival betamethasone (Betnesol, Glaxo) given at the end of cataract surgery, both in normal patients and in those with risk factors for an exaggerated post-operative inflammatory response.

\section{PATIENTS AND METHODS}

Two hundred and forty-six patients were recruited from those undergoing routine in-patient cataract extraction who gave informed consent. All underwent a full ophthalmic and general medical history and examination, with particular note being made of their race and iris colour. The exclusion criteria were:

1. Active intraocular inflammation.

2. Topical or systemic administration of steroids or nonsteroidal anti-inflammatory agents in the month preceding surgery.

3. Allergy to any of the drug components used.

Patients were assigned to the groups 'Uncomplicated' (180 patients), 'Diabetic' (42) or 'Previous intraocular inflammation or surgery' (24). The latter consisted of patients who had significant corneal scarring (3), old blunt trauma (4), surgery for ipsilateral angle closure glaucoma (5), other glaucoma surgery (6), or previous anterior uveitis (6). In no case had active inflammation been present in the month preceding surgery. Patients of the uncomplicated group were further divided into subgroups according to their risk factors for an exaggerated inflammatory response. ${ }^{8}$ Within each main group, patients were randomised to receive either subconjunctival betamethasone or placebo at the end of surgery.

Cataract extraction was performed by either extracapsular or phacoemulsification ( $7 \mathrm{~mm}$ incision) techniques, using hydroxypropyl methylcellulose 2\% (HPMC) or sodium hyaluronate $10 \%$, and insertion of a one-piece polymethyl methacrylate (PMMA) intraocular lens. The 
Table I. Ease of surgery: definitions of the categories used

\begin{tabular}{ll}
\hline Ease & Definition \\
\hline Easy & No difficulty with any stage of surgery \\
Slightly difficult & Difficulty with one stage of surgery, e.g. \\
& Small pupil \\
& Persistently shallow anterior chamber \\
& Difficult/prolonged cortex aspiration \\
& Persistent iris prolapse \\
& Difficult/traumatic lens insertion \\
& Anterior chamber haemorrhage \\
& Difficulty with two or more stages \\
Complicated & Posterior lens capsule rupture \\
& Vitreous loss \\
\hline
\end{tabular}

ease of surgery was graded as 'easy', 'slightly difficult' or 'complicated' (Table I).

At the end of surgery each patient received a $0.8 \mathrm{ml}$ subconjunctival injection of cefuroxime $75 \mathrm{mg}$ with either Betnesol $2 \mathrm{mg}$ or placebo (sterile water). Standard post-operative treatment was with G. Betnesol N (betamethasone $0.1 \%$ and neomycin $0.5 \%$ ) four times a day for 2 weeks, then twice a day for 2 weeks. Additional treatment was prescribed if clinically indicated, and recorded as the total number of extra steroid drops used by each patient during the 2-month follow-up period.

The patients were examined on days 1, 2, 14 and 56 post-operatively, by three masked observers whose subjective grading was standardised before and at intervals throughout the study. On each occasion measurements were made of Snellen visual acuity, intraocular pressure and corneal thickness; and the presence or absence of corneal epithelial oedema and cystoid macular oedema was noted. The inflammatory response was graded according to a modification of the system proposed by Hogan et al. ${ }^{11}$ (Table II). This grading system correlates with measurements by the laser flare-cell meter, ${ }^{12,13}$ but is practical for surgeons in the clinical setting. An overall inflammation score was calculated by summation of the grades for conjunctival injection, cells and flare.

The length of in-patient stay was recorded in two ways: firstly, as the post-operative day on which the level of inflammation would have allowed safe discharge; and secondly, the post-operative day on which the patient was fit to go home, considering all ophthalmic features.

The effects of subconjunctival betamethasone were assessed by comparing these findings in patients receiving the drug with those receiving placebo, using an unpaired Student's $t$-test. ${ }^{14}$ These comparisons were made within each of the three main groups (uncomplicated, diabetic and previous inflammation) and for the subgroups of the uncomplicated category (race, iris colour, type of operation and ease of surgery.

\section{RESULTS}

Analysis of the demographic data for the three main groups (Table III) shows that patients with diabetes or previous intraocular inflammation tended to undergo cataract

Table II. Grading of post-operative inflammatory signs. Summation of the grade for each sign gives the inflammation score

\begin{tabular}{|c|c|c|c|}
\hline Grade & Conjunctival injection & Cells in anterior chamber & Flare in anterior chamber \\
\hline 0 & Completely white & Completely quiet & Completely absent \\
\hline 1 & $1-2$ quadrants & WBC $<10 /$ field & Just detectable \\
\hline 2 & $>2$ quadrants or episcleral vessels & WBC 10-20/field & Iris details clear \\
\hline 3 & Diffuse and intense + episcleral vessels & WBC $>20 /$ field & Iris details hazy or fibrin \\
\hline 4 & & Hypopyon & Fixed coagulated aqueous \\
\hline
\end{tabular}

WBC, white blood cells; field $=1 \times 3 \mathrm{~mm}$ slit lamp beam of maximal intensity, viewed under $\times 16$ magnification.

Table III. Demographic features of the three main groups of patients

\begin{tabular}{|c|c|c|c|c|c|c|}
\hline \multirow{2}{*}{$\frac{\text { Patients }}{\text { Total no. }}$} & \multicolumn{2}{|c|}{ Uncomplicated } & \multicolumn{2}{|c|}{ Diabetic } & \multicolumn{2}{|c|}{ Previous inflammation } \\
\hline & 180 & $(90,90)$ & 42 & $(21,21)$ & 24 & $(12,12)$ \\
\hline Age (mean, years) & 74.8 & $(74,75)$ & 70.2 & $(70,70)$ & 65.3 & $(56,74)$ \\
\hline Males & $31 \%$ & $(34,32)$ & $50 \%$ & $(9,12)$ & $50 \%$ & $(7,5)$ \\
\hline Local anaesthetic & $71 \%$ & $(61,67)$ & $86 \%$ & $(17,19)$ & $46 \%$ & $(4,7)$ \\
\hline \multicolumn{7}{|l|}{ Race } \\
\hline Caucasian & $93.0 \%$ & $(84,83)$ & $71 \%$ & $(14,16)$ & $84 \%$ & $(10,10)$ \\
\hline African & $1.6 \%$ & $(1,2)$ & $0 \%$ & & $4 \%$ & $(1,0)$ \\
\hline Asian & $2.2 \%$ & $(2,2)$ & $12 \%$ & $(3,2)$ & $8 \%$ & $(1,1)$ \\
\hline Far Eastern & $0.6 \%$ & $(0,1)$ & $0 \%$ & & $0 \%$ & \\
\hline West Indian & $2.6 \%$ & $(3,2)$ & $17 \%$ & $(4,3)$ & $4 \%$ & $(0,1)$ \\
\hline \multicolumn{7}{|l|}{ Eye colour } \\
\hline Blue & $53 \%$ & $(52,44)$ & $28 \%$ & $(5,6)$ & $30 \%$ & $(4,3)$ \\
\hline Hazel & $30 \%$ & $(22,32)$ & $32 \%$ & $(5,8)$ & $37 \%$ & $(3,6)$ \\
\hline Brown & $17 \%$ & $(16,14)$ & $40 \%$ & $(11,7)$ & $33 \%$ & $(5,3)$ \\
\hline \multicolumn{7}{|l|}{ Operation } \\
\hline Extracapsular & $81 \%$ & $(75,70)$ & $79 \%$ & $(17,16)$ & $92 \%$ & $(11,11)$ \\
\hline Phacoemulsification & $19 \%$ & $(15,20)$ & $21 \%$ & $(4,5)$ & $8 \%$ & $(1,1)$ \\
\hline \multicolumn{7}{|l|}{ Ease of surgery } \\
\hline Easy & $76 \%$ & $(69,67)$ & $74 \%$ & $(15,16)$ & $50 \%$ & $(6,6)$ \\
\hline Difficult & $21 \%$ & $(18,20)$ & $21 \%$ & $(5,4)$ & $42 \%$ & $(4,6)$ \\
\hline Complicated & $3 \%$ & $(3,3)$ & $5 \%$ & $(1,1)$ & $8 \%$ & $(2,0)$ \\
\hline
\end{tabular}

The percentages express the proportion of patients in each main group with a given characteristic. The actual numbers of patients are recorded in brackets: (number receiving betamethasone, number receiving placebo). 
Table IV. Mean post-operative outcome for patients receiving betamethasone (B) and placebo (P) for each of the three main groups

\begin{tabular}{|c|c|c|c|c|c|c|}
\hline \multirow[b]{2}{*}{ Outcome } & \multicolumn{2}{|c|}{ Uncomplicated } & \multicolumn{2}{|c|}{ Diabetic } & \multicolumn{2}{|c|}{ Previous inflammation } \\
\hline & $\mathrm{B}$ & $\mathrm{P}$ & $\mathrm{B}$ & $\mathrm{P}$ & $\mathrm{B}$ & $\mathrm{P}$ \\
\hline Total no. & 90 & 90 & 21 & 21 & 12 & 12 \\
\hline $\begin{array}{l}\text { First post-operative day } \\
\text { Conjunctival injection } \\
\text { Cells } \\
\text { Flare } \\
\text { Inflammation score }\end{array}$ & $\begin{array}{l}1.33 \\
1.79 \\
1.64 \\
4.82\end{array}$ & $\begin{array}{l}1.57^{* *} \\
1.91 \\
1.78 \\
5.27^{*}\end{array}$ & $\begin{array}{l}1.29 \\
1.81 \\
1.86 \\
4.95\end{array}$ & $\begin{array}{l}1.33 \\
1.71 \\
1.71 \\
4.76\end{array}$ & $\begin{array}{l}1.17 \\
1.58 \\
1.42 \\
4.17\end{array}$ & $\begin{array}{l}1.92 * * \\
2.33 * \\
2.17 * \\
6.42 * *\end{array}$ \\
\hline $\begin{array}{l}\text { Management } \\
\text { In-patient stay (inflammation) } \\
\text { In-patient stay (all causes) } \\
\text { Extra drops }\end{array}$ & $\begin{array}{l}1.02 \\
1.11 \\
0.71\end{array}$ & $\begin{array}{l}1.11^{*} \\
1.26 * \\
2.20\end{array}$ & $\begin{array}{l}1.05 \\
1.10 \\
1.52\end{array}$ & $\begin{array}{l}1.05 \\
1.10 \\
4.00\end{array}$ & $\begin{array}{l}1.25 \\
1.42 \\
0\end{array}$ & $\begin{array}{c}2.08 \\
2.08 \\
34.4^{*}\end{array}$ \\
\hline
\end{tabular}

Results of the two treatments are compared within each of the groups using an unpaired Student's $t$-test $(* p<0.05 ; * * p<0.01)$.

extraction at an earlier age than uncomplicated cases, and that the female preponderance was lost. Diabetics often received local anaesthetics, but in previously inflamed cases general anaesthesia was more frequently used. There was a higher proportion of non-Caucasian patients in the diabetic and previously inflamed categories than in the uncomplicated group, and this was associated with a greater percentage of patients having brown irises. Of the cases with previous intraocular inflammation, relatively few had cataract removal performed by phacoemulsification, and in a higher proportion the surgery was described as difficult or complicated. These demographic features are evenly distributed between the patients receiving betamethasone or placebo, within each group.

Table IV shows the effect of subconjunctival betamethasone on early post-operative outcome for each of the three main groups. In the uncomplicated group, patients receiving betamethasone had a significantly lower inflam-

Table V. Relative benefits of betamethasone in the uncomplicated subgroups, expressed as differences between the means for patients receiving betamethasone and placebo (placebo - betamethasone)

\begin{tabular}{|c|c|c|c|}
\hline Subgroup & $\begin{array}{l}\text { Inflammation } \\
\text { score on } \\
\text { day } 1\end{array}$ & $\begin{array}{c}\text { In-patient } \\
\text { stay for } \\
\text { inflammation }\end{array}$ & $\begin{array}{c}\text { No. of } \\
\text { extra drops }\end{array}$ \\
\hline \multicolumn{4}{|l|}{ Groups } \\
\hline Uncomplicated & 0.45 & 0.06 & 1.49 \\
\hline Diabetics & -0.19 & 0 & 3.48 \\
\hline Previous inflammation & $2.25+++$ & $0.83+++$ & $34.4+++$ \\
\hline \multicolumn{4}{|l|}{ Uncomplicated subgroups } \\
\hline \multicolumn{4}{|l|}{ Race } \\
\hline Caucasian & 0.40 & 0.07 & -0.18 \\
\hline Non-Caucasian & $1.07++$ & $0.43++$ & $21.43++$ \\
\hline \multicolumn{4}{|l|}{ Iris colour } \\
\hline Blue & 0.59 & 0.07 & 0.29 \\
\hline Hazel & 0.36 & 0.03 & -1.02 \\
\hline Brown (Caucasian) & -0.86 & 0.18 & 0.71 \\
\hline Brown (all races) & 0.06 & $0.29+$ & $10.44+$ \\
\hline \multicolumn{4}{|l|}{ Operation } \\
\hline Extracapsular & 0.27 & 0.13 & 2.78 \\
\hline Phacoemulsification & -0.28 & -0.06 & -4.00 \\
\hline \multicolumn{4}{|l|}{ Ease of surgery } \\
\hline Easy & 0.38 & -0.03 & 0.41 \\
\hline Difficult/complicated & $0.58+$ & $0.26+$ & $4.55+$ \\
\hline
\end{tabular}

,+++++ and + reflect the relative amount of benefit derived from betamethasone compared with the other subgroups. mation score $(4.82$ vs. $5.27, p<0.05)$ on the first postoperative day (Fig. 1), and a shorter in-patient stay $(p<0.05)$. In diabetics, subconjunctival betamethasone made little difference to post-operative inflammation (Fig. 2) or patient management. Greatest benefit from the injection was seen in the previous inflammation group (Fig. 3), with significant benefit from betamethasone being achieved individually for injection, cells and flare (mean overall score 4.17 vs. $6.42, p<0.01$ ). In-patient stay due to inflammation was reduced by an average of almost 1 day, and no patients receiving subconjunctival betamethasone required extra drops.

Further analysis of the uncomplicated patients by subgroup (Table V) shows that subconjunctival betamethasone produces most benefit in non-Caucasians and in those with difficult or complicated surgery. The magnitude of the response was independent of iris colour in Caucasians, and the type of surgery.

After the first post-operative day there was no significant difference in anterior segment inflammation between those receiving betamethasone and placebo, in any of the three groups. At no time did betamethasone significantly

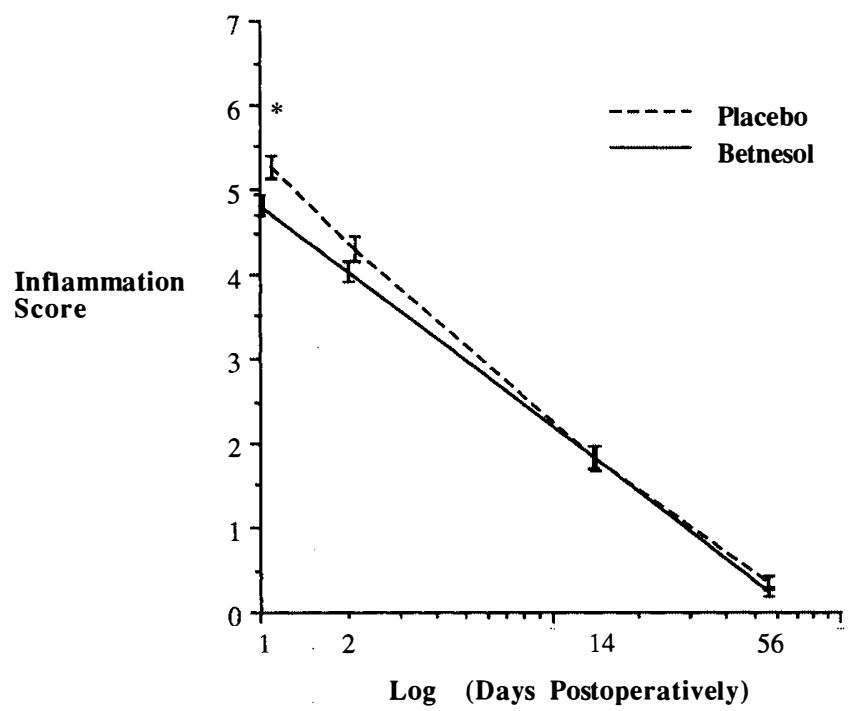

Fig. 1. Average post-operative inflammation scores for patients in the uncomplicated group (mean with standard error bars, $\left.{ }^{*} p<0.05\right)$. 


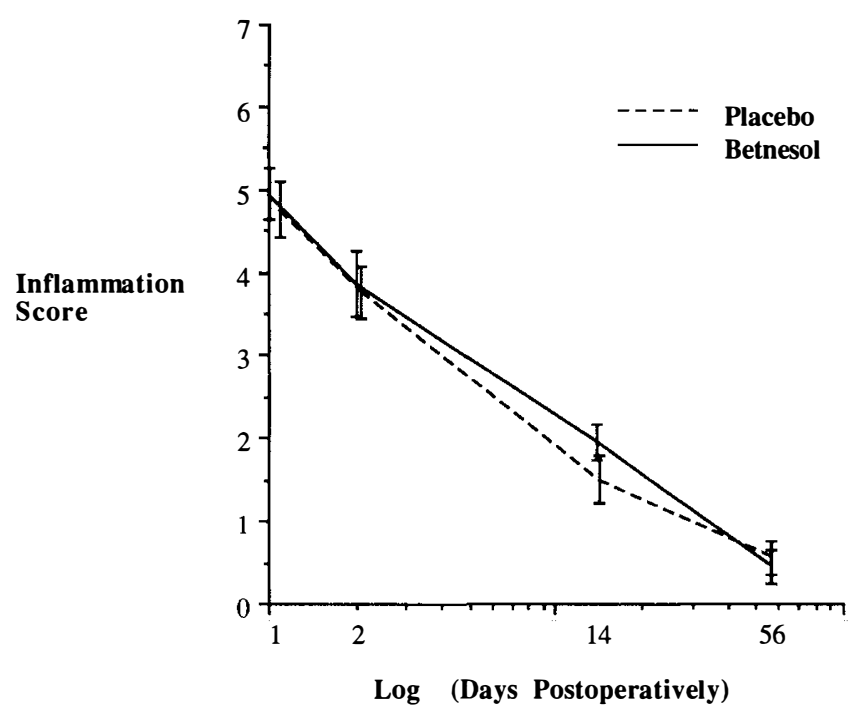

Fig. 2. Average post-operative inflammation scores for diabetic patients (mean with standard error bars; at no time were the values for betamethasone and placebo significantly different).

alter visual acuity, corneal epithelial oedema or pachymetry, intraocular pressure or cystoid macular oedema. No patients in the study suffered either post-operative iris prolapse, wound dehiscence or endophthalmitis.

\section{DISCUSSION}

Inflammation in the eye is damaging, and must therefore be adequately managed. ${ }^{8}$ A variety of regimes ${ }^{15}$ are used for the prophylaxis and treatment of the inflammation which follows cataract extraction. Most surgeons give a course of a topical anti-inflammatory agent during the first few post-operative weeks; but there is still debate as to whether prophylaxis needs to be given immediately at the end of surgery, and whether this should take the form of drops or a subconjunctival injection.

Following a single drop of topical steroid, absorption occurs through the cornea, and peak aqueous levels are reached at 90-120 minutes. ${ }^{16,17}$ Steroid from a subconjunctival injection site can enter the eye either via the sclera, ${ }^{18}$ or by diffusing through the puncture site into the conjunctival sac, and thence through the cornea. ${ }^{19}$ High concentrations of steroid in the anterior chamber can be achieved by this route. ${ }^{20,21}$

Topical steroid, if given frequently, has been shown to be more effective than a single subconjunctival injection at suppressing corneal inflammation in rabbits. ${ }^{18}$ However, most surgeons cover the operated eye for 16-24 hours following cataract surgery, and frequent instillation of drops is therefore not feasible. In this situation, a subconjunctival injection given at the end of surgery, during the period of anaesthesia, provides a practical and painless means of maintaining steroid cover during the early post-operative phase when intraocular inflammation becomes active. A larger dose can be given by the subconjunctival than the topical route, and absorption occurs over a longer period.

Of patients in the uncomplicated group, those receiving betamethasone had significantly less post-operative inflammation and a shorter in-patient stay than those receiving placebo. They also received fewer extra drops, although the difference did not reach significance level for the group as a whole. The benefits of the subconjunctival injection are most marked in those patients prone to a greater inflammatory response: especially those with previous intraocular inflammation, but also those of nonCaucasian race or in whom surgery was difficult. The magnitude of the response to betamethasone was independent of iris colour in Caucasians, and the type of surgery.

The only group in which no benefit was demonstrated was the diabetics. This may be due to the relatively small number of patients in the group, or it may reflect a difference in the inflammatory response between diabetic and non-diabetic patients.

There was no significant difference in the inflammation score after the first post-operative day. This is thought to be mainly due to exaggerated inflammatory responses being adequately treated by increasing the frequency of post-operative steroid drops.

A recent study concluded that patients receiving prophylaxis by a subconjunctival injection (Betnesol $2 \mathrm{mg}$ plus gentamicin $20 \mathrm{mg}$ ) at the end of cataract surgery had more post-operative inflammation than patients receiving a single drop (Betnesol $0.1 \%$ plus neomycin $0.5 \%) .^{22}$ These results may be due firstly to the inclusion of subconjunctival haemorrhage in the clinical grading of conjunctival injection; and secondly to the use of gentamicin in the subconjunctival injection but not the drops. Gentamicin is one of the more toxic antibiotics, and has been proven to produce significantly more hyperaemia than cefuroxime when administered subconjunctivally. ${ }^{23}$ A couple of months later, a controlled trial of subconjunctival cefuroxime with or without betamethasone failed to find a difference between two groups of 10 patients, using the laser flare-cell meter. ${ }^{24}$

There are a number of possible complications of ocular

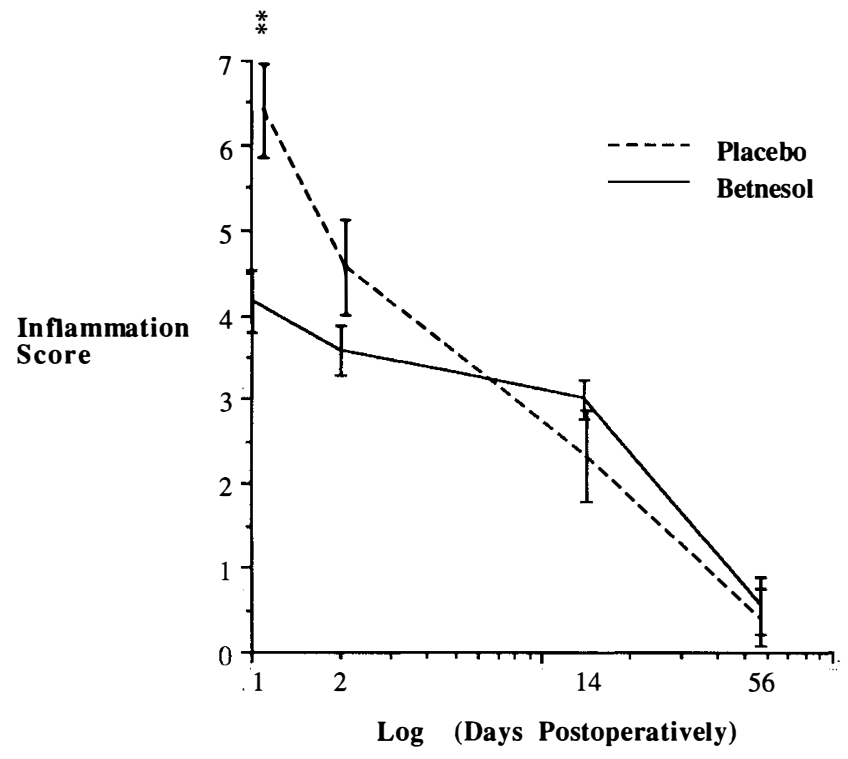

Fig. 3. Average post-operative inflammation scores for patients with previous intraocular inflammation (mean with standard error bars; $\left.{ }^{* *} p<0.01\right)$. 
steroid administration. Susceptible subjects may develop raised intraocular pressure, ${ }^{25-27}$ but usually this is easily controlled by topical or oral hypotensive agents. ${ }^{28}$ Depot injections of corticosteroid have been shown to remain active for days, ${ }^{21}$ and the pressure may be elevated as long as the steroid material remains visible. ${ }^{28}$ Water-soluble preparations such as Betnesol have a shorter duration of action and are therefore less likely to affect the intraocular pressure. However, we found no significant difference in the intraocular pressures of those who received Betnesol and those who did not.

Steroids are also known to affect wound healing. In a rabbit model, the tensile strength of a central corneal wound 3 weeks post-operatively was reduced by topical steroids given during the first week. ${ }^{29}$ The importance of these findings to a peripheral corneal or scleral section is unknown. Conversely, a human study reported a reduced incidence of wound dehiscence or iris prolapse, but this was by comparison of the literature with the results of 200 patients receiving repository corticosteroids after intracapsular surgery. ${ }^{30}$ In our study, neither of these complications were seen.

A theoretical complication of steroid use is an increased risk of infection, but this may be reduced by the use of prophylactic antibiotics. ${ }^{31-33}$ In our study there were no cases of endophthalmitis, but given the rarity of this complication, a much larger study would be needed to demonstrate any effect of subconjunctival steroids on its incidence.

In conclusion, subconjunctival injection of betamethasone (Betnesol) at the end of cataract surgery significantly reduces intraocular inflammation on the first post-operative day, with no evidence of adverse effects. It also reduces in-patient stay and the need for additional steroid treatment. Most benefit was seen in those patients prone to a greater inflammatory response. Subconjunctival injection of betamethasone is therefore a practical, safe and effective means of improving the quality and efficiency of post-operative patient care.

Key words: Cataract surgery, Day case surgery, Inflammation. Prophylaxis, Steroids.

\section{REFERENCES}

1. Jaffe NS. Current concepts in posterior chamber lens technology. J Am Intraocul Implant Soc 1985;11:456-60.

2. Goodman DF, Stark WJ, Gottsch JD. Complications of cataract extraction with intraocular lens implantation. Ophthalmic Surg 1989;20:132-40.

3. Hardten DR, Lindstrom RL. Complications of cataract surgery. Int Ophthalmol Clin 1992;32:131-55.

4. Vernon SA, Cheng H. Comparison between the complications of cataract surgery following local anaesthesia with short stay and general anaesthesia with five-day hospitalisation. Br J Ophthalmol 1985;69:360-3.

5. Ingram RM. Day-case ophthalmic surgery. J R Soc Med 1984;77:263-5.

6. Steele ADMcG. Cataract management [editorial]. Br J Ophthalmol 1992;76:321.

7. Hodgkins PR, Luff AJ, Morrell AJ, Teye Botchway L, Featherston TJ, Fielder AR. Current practice of cataract extraction and anaesthesia. Br J Ophthalmol 1992;76:323-6.

8. Corbett MC, Hingorani M, Boulton JE, Shilling JS. Factors predisposing to inflammation following cataract surgery. $\mathrm{Br}$ J Ophthalmol (under review).
9. Hooper PL, Rao NA, Smith SR. Cataract extraction in uveitis patients. Surv Ophthalmol 1990;35:120-44.

10. Krupsky S, Zalish M, Oliver M, Pollack A. Anterior segment complications in diabetic patients following extracapsular cataract extraction and posterior chamber lens implantation. Ophthalmic Surg 1991;22:526-30.

11. Hogan MJ, Kimura SJ, Thygeson P. Signs and symptoms of uveitis. I. Anterior uveitis. Am J Ophthalmol 1959;47:155-70.

12. Sawa M. Clinical application of laser flare-cell meter. Jpn J Ophthalmol 1990;34:346-63.

13. El-Maghraby A, Marzouki A, Matheen TM, Souchek J, Van der Karr M. Reproducibility and validity of laser flare/cell meter measurements as an objective method of assessing intraocular inflammation. Arch Ophthalmol 1992;1 10:960-2.

14. Moses LE, Emerson JD, Hosseini H. Analysing data from ordered categories. N Engl J Med 1984;311:442-8.

15. McGhce NJ. Pharmacokinetics of ophthalmic corticosteroids. Br J Ophthamol 1992;76:681-4.

16. Watson DG, McGhee CNJ, Midgley JM, Dutton GN, Nobel MJ. Penetration of topically applied betamethasone sodium phosphate into human aqueous humour. Eye 1990;4:603-6.

17. McGhee CNJ, Watson DG, Midgley JM, Nobel MJ, Dutton GN, Fern AI. Penetration of synthetic corticosteroids into human aqueous humour. Eye 1990;4:526-30.

18. Leibowitz HM, Kupferman A. Periocular injection of corticosteroids. Arch Ophthalmol 1977;95:311-4.

19. Wine NA, Gornall AG, Basu PK. The ocular uptake of subconjunctivally injected ${ }^{1+} \mathrm{C}$-hydrocortisone. Am J Ophthalmol 1964;58:362-5.

20. Tsuji A, Tamai I, Sasaki K. Intraocular penetration kinetics of prednisolone after subconjunctival injection in rabbits. Ophthalmic Res 1988;20:31-43.

21. Hynduik RA. Radioactive depot-corticosteroid penetration into monkey ocular tissue. Arch Ophthalmol 1969;82: 259-62.

22. Sanders R, Macewen CJ, Haining WM. A comparison of prophylactic, topical and subconjunctival treatment in cataract surgery. Eye 1992;6:105-10.

23. Jenkins CDG, McDonnell PJ, Spalton DJ. Randomised single blind trial to compare the toxicity of subconjunctival gentamicin and cefuroxime in cataract surgery. Br J Ophthalmol 1990;74:734-8.

24. Shah SM, McHugh JD, Spalton DJ. The effects of subconjunctival betamethasone on the blood-aqueous barrier following cataract surgery: a double-blind randomised prospective study. Br J Ophthalmol 1992;76:475-8.

25. Becker B, Mills DW. Corticosteroids and intraocular pressure. Arch Ophthalmol 1963;70:500-7.

26. Armaly MF. Effects of corticosteroids on intraocular pressure and fluid dynamics. I. The effect of dexamethasone in the normal eye. Arch Ophthalmol 1963;70:482-91.

27. Kwitko ML. Postoperative open-angle glaucoma following topical application of steroids. Can Med Assoc J 1966;94: 966-7.

28. Kalina RE. Increased intraocular pressure following subconjunctival corticosteroid administration. Arch Ophthalmol 1969;81:788-90.

29. Sugar J, Chandler JW. Experimental corneal wound strength: effect of topically applied corticosteroids. Arch Ophthalmol 1974;92:248-9.

30. Buxton JN, Smith DE, Brownstein S. Cataract extraction and subconjunctival repository corticosteroids. Ann Ophthalmol 1971;3:1376-9.

31. Pearlman MD. Prophylactic subconjunctival penicillin and streptomycin after cataract extraction. Arch Ophthalmol 1956;55:516-8.

32. Kolker AE, Freeman MI, Pettit TH. Prophylactic antibiotics and post-operative endophthalmitis. Am J Ophthalmol 1967;63:434-9.

33. Allen HF, Mangiaracine AB. Bacterial endophthalmitis after cataract extraction. Arch Ophthalmol 1974;91:3-7. 